\title{
Pre-Operative Status and Quality of Life Following Total Joint Replacement in a Developing Country: A Prospective Pilot Study
}

\author{
Nina N. Niu ${ }^{*}, 1,2$, Jamie E. Collins ${ }^{1,2,6}$, Thomas S. Thornhill ${ }^{2}$, Luis Alcantara Abreu ${ }^{7}$, \\ Roya Ghazinouri ${ }^{4}$, Kanu Okike ${ }^{2}$ and Jeffrey N. Katz ${ }^{1,2,3,5}$
}

${ }^{I}$ Orthopedic and Arthritis Center for Outcomes Research, Brigham and Women's Hospital, 75 Francis St., Boston, MA 02115 , USA

${ }^{2}$ Department of Orthopedic Surgery, Brigham and Women's Hospital, 75 Francis St., Boston, MA 02115, USA

${ }^{3}$ Division of Rheumatology, Immunology and Allergy, Brigham and Women's Hospital, 75 Francis St., Boston, MA 02115, USA

${ }^{4}$ Department of Rehabilitation Services, Physical Therapy, Brigham and Women's Hospital, 75 Francis St., Boston, MA 02115, USA

${ }^{5}$ Harvard School of Public Health, 677 Huntington Ave., Boston, MA 02115, USA

${ }^{6}$ Department of Biostatistics, Boston University School of Public Health, 715 Albany Street, Talbot Building, Boston MA 02118 , USA

${ }^{7}$ Department of Orthopedic Surgery, Hospital General de la Plaza de la Salud, Santo Domingo, Dominican Republic

\begin{abstract}
Background: An increasing number of medical relief organizations have launched programs to perform total joint replacements in the developing world. There is a paucity of data on the clinical outcomes of these procedures. We documented pre- and post-operative pain and functional status in a group of low income Dominicans who underwent total hip or knee replacement performed by an American relief organization.

Methods: In March 2009 and 2010, we surveyed patients participating in Operation Walk Boston, a medical relief organization that provides total joint replacements to patients in the Dominican Republic. Questionnaires included the Western Ontario and McMaster University Osteoarthritis (WOMAC) Index scales and the Short-Form 36 (SF-36) scales for physical activity and mental health. Scores were transformed to a 0 - 100 point scale (100 is best).

Results: 81 individuals (mean age 61 years, $60 \%$ female) completed the pre-operative questionnaires. Twenty eight of the 35 who completed preoperative forms in 2009 also completed follow up forms in 2010 (follow-up rate 80\%). Patients reported poor pre-operative WOMAC function (mean $=33.6, \mathrm{sd}=22.0)$ and WOMAC pain $($ mean $=38.4, \mathrm{sd}=22.9)$ scores preoperatively. Mean post-operative WOMAC pain and function scores were $86.4(\mathrm{sd}=13.1)$ and $88.1(\mathrm{sd}=11.4)$ respectively. Improvement in pain and function was similar for patients undergoing hip $(\mathrm{n}=11)$ and knee $(\mathrm{n}=17)$ replacements.

Conclusion: Total joint replacement was effective in relieving pain and restoring function in this program. These results are useful for comparison to outcomes in developed countries and for establishing benchmarks for future programs.
\end{abstract}

Keywords: Arthritis, total joint replacement, global health, quality-of-life.

\section{INTRODUCTION}

Arthritis is a common cause of severe pain and functional limitation that affects hundreds of millions of individuals worldwide [1]. The growing prevalence of obesity has lead to a global increase in arthritis. In developing nations specifically, the improved ability to treat infectious diseases and prevent other causes of early mortality has lengthened life expectancy and increased the burden of chronic conditions including arthritis [2]. While disease-modifying anti-

*Address correspondence to this author at the Orthopedic and Arthritis Center for Outcomes Research, Brigham and Women's Hospital, 75 Francis St., Boston, MA 02115, USA; Tel: 617-645-7289;

E-mail: Nina_Niu@hms.harvard.edu rheumatic drugs slow the progression of rheumatoid arthritis (RA), no such therapeutics are currently available for osteoarthritis (OA), the most prevalent form of arthritis. For both conditions, total joint replacement (TJR) is the treatment of choice for individuals with advanced structural damage, severe pain and functional limitation [3-13].

Total joint replacement is frequently performed in the US, with over one million hip and knee replacements operations carried out annually [14]. Research on TJR outcomes in developed countries suggests that patients with worse functional status at the time of surgery tend to have worse outcomes $[15,16]$. Studies also document marked gender and racial disparities in access to and preference for surgery: women tend to present for surgery at a more 
advanced stage of functional decline $[17,18]$ and rates of TJR are significantly higher among white patients as compared with African American patients of similar disease status [19]. In developing countries, however, access to TJR is constrained by the limited resources and availability of trained surgeons, and outcome data are scarce. To address these gaps in technical expertise, medical relief organizations have begun to launch programs to perform TJR on resident populations in developing countries. These programs educate host facilities about the procedure with the eventual goal of enabling them to develop autonomous joint replacement programs. Similar initiatives are occurring in other fields of medicine [20]. The clinical results of these medical service and education initiatives have not yet been critically evaluated. Such outcome data would be useful to determine whether patients treated by these relief organizations experience outcomes comparable to those achieved in developed countries. These data would also establish a benchmark for comparison of outcomes as programs evolve toward greater independence of the host surgeons and care teams.

The goal of this paper is to document the outcomes of TJR performed on a cohort of Dominican patients by surgeons of Operation (Op) Walk Boston, a not for profit medical relief organization that performs joint replacements upon approximately 45 Dominican patients annually with advanced hip or knee arthritis. In March 2009 and March 2010, OpWalk Boston operated upon a total of 88 patients. We obtained data on pre-operative pain and functional for these patients and analogous post-operative data one year following TJR for members of the 2009 cohort. In this paper, we report on pre-operative severity and changes in status in this joint replacement population. We also assess the internal consistency of the scales used to measure pain and functional status in order to validate the use of these scales in this developing world context. Through empirical evaluation of the effects of TJR on health-related quality of life in this cohort, we hope to set a benchmark for future initiatives to transfer TJR to the developing world setting.

\section{MATERIALS AND METHODOLOGY}

\section{Setting}

We performed a prospective cohort study of patients undergoing total knee and hip replacement as part of the Operation (Op) Walk Boston program in Santo Domingo, Dominican Republic. The Dominican Republic occupies the eastern $2 / 3$ of the island Hispaniola, located between the Caribbean Sea and the North Atlantic Ocean. The population of the nation is approximately 9.8 million, with roughly 4.1 million citizens $(42 \%)$ living below the international poverty line. The Gross Domestic Product of the country is roughly $18 \%$ of that in the United States. While all citizens are covered by a public healthcare system, only basic healthcare needs are included in this plan and advanced treatments such as TJR are generally not accessible to the poor [21].

\section{Patients}

All patients participating in Operation Walk 2009 and Operation Walk 2010 were eligible for the study. The poorest patients who could not have paid for the operation and who were medically eligible were accepted into the program. To determine medical eligibility, patient radiographs and medical records were reviewed by surgeons in both the US and the Dominican Republic to ensure that the patient had advanced symptomatic hip or knee arthritis. Medical care occurred at Hospital General de la Plaza de la Salud in Santo Domingo from March $11-16,2009$ and March 17 - 24, 2010.

\section{Power}

The fixed sample size of 28 patients who were evaluated pre- and post-operatively permitted us $80 \%$ to detect differences in mean WOMAC pain scores of 12 points between men and women with a standard deviation of 20 and Type I error of $5 \%$.

\section{Intervention}

All patients in the cohort underwent unilateral or bilateral hip or knee TJR. Following surgery, patients remained in the hospital for one to two nights and returned to the hospital 10 days post-operatively for removal of sutures. Patients were prescribed physical therapy exercises to complete in their homes. Patients received follow-up care from a Dominican surgeon who is a leading member of OpWalk Boston. One year post-operatively, the patients were re-evaluated by the entire OpWalk team including orthopedic surgeons, physical therapists, and nurses from the United States.

\section{Data Collection Procedures}

Research associates approached the pre-operative patients on the first day they were admitted to the hospital. Post-operative patients were surveyed while they were waiting to be seen by a clinician for their one year follow-up appointments. Research associates provided the patients with an introductory study letter and further explained the study to interested patients. Those who chose to participate signed a consent letter before filling out the questionnaire. One investigator surveyed the patients pre-operatively in 2009; another investigator gathered data in 2010 on one year postoperative patients from 2009 and patients undergoing TJR in 2010.

\section{Survey Instrument}

The pre-operative questionnaire included demographic details (age, gender, marital status, living arrangements, employment, and level of education), and items on patients' perception of TJR (the patient's perceived probability that the surgery would relieve pain and the probability that they would suffer from a complication during the operation). The one year post-operative questionnaire included a section on improvement in quality of life following surgery and satisfaction with surgery.

Both pre- and post-operative questionnaires incorporated the physical activity and the mental health subscales scales of the Short-Form 36 (SF-36) [22-24] and the Western Ontario and McMaster University Osteoarthritis Index (WOMAC) $[25,26]$. Both are validated indices of health and functional status and have been used extensively in studies of total joint replacement [5, 15, 27-32]. We transformed scores from these measures to a 0 to 100 -point scale (with 100 being the best score) 
The surveys were written in Spanish. We used published Spanish versions of the SF-36 and WOMAC indices [33, 34]. All other items, such as those on demographics, or expectations of surgery, were translated by the bilingual researchers of this study.

\section{Statistical Methods}

\section{Internal Consistency of Scales}

We assessed the reliability (internal consistency) of the SF-36 and WOMAC indices at baseline and one year postoperatively with Cronbach's alpha. A high Cronbach's alpha coefficient (generally >0.7) indicates that a set of items measures a single, underlying unidimensional construct [35]. We also divided the cohort into those who had finished secondary school and those who had not to examine whether differences in internal consistency were associated with education.

\section{Pre-Operative Clinical Characteristics}

To document pre-operative health status of the patients undergoing TJR, we calculated pre-operative scores for WOMAC pain and function status scales and SF-36 physical activity and mental health status scales. We assessed the association between sex, age and unilateral $v s$ bilateral surgery, and hip $v s$ knee replacements with the pre-operative scores. These analyses were performed using t-tests for normally distributed variables and the Wilcoxon Rank Sum test for variables that were not normally distributed. All data were analyzed using SAS version 9.2.

\section{Post-Operative Clinical Characteristics}

We calculated post-operative WOMAC pain, stiffness and function, and SF-36 physical function and mental health status scores for patients we surveyed in the 2009 cohort who returned for follow-up in 2010. We compared outcomes in patients undergoing hip $v s$ knee replacements, compared outcomes in patients undergoing hip $v s$ knee replacements, and also asked patients about their overall satisfaction with surgery.

Our study conforms to ethical principles of the Declaration of Helsinki. All research was approved by the institutional review boards at the Brigham and Women's Hospital and Hospital General de la Plaza de Salud.

\section{RESULTS}

\section{Recruitment}

In the 2009 cohort, 35 out of $42(83 \%)$ eligible patients enrolled in the study. Seven patients were not enrolled because they were sent to the operating room before the research associate was able to approach them. In the 2010 cohort, all 46 out of the 46 eligible patients $(100 \%)$ were enrolled. In total, 81 of 88 (92\%) pre-operative patients were enrolled over the two years, including 55 patients undergoing total knee replacement and 26 patients undergoing total hip replacement. At the follow-up evaluation in 2010, 33 follow-up patients who had received their operations in 2009 returned for an evaluation while 9 follow-up patients did not attend the follow-up clinic in 2010. Five of the 33 returning patients were not surveyed pre-operatively in 2009, yielding 28 patients (11 hips,
17 knees) who filled out both pre- and post- op surveys. The follow-up rate was $80 \%$ ( 28 of 35). The age and gender of this group who had both baseline and follow-up data did not differ significantly from the cohort with baseline data who did not participate in the one year follow-up. However, a greater proportion of these 28 follow-up patients (46.4\%) received bilateral joint replacements as compared to the patients for whom we did not obtain follow-up data (26.4\%).

\section{Demographic, Socioeconomic and Clinical Characteristics of Patients (Table 1)}

The mean age of the patients in the pre-operative cohort was 61 years (range $=21$ to 80 years). Fifty-five $(67.9 \%)$ patients underwent total knee replacement and $54(66.6 \%)$ of patients received a unilateral prosthesis. Over $90 \%$ of the patients had OA and the remainder were RA patients. The majority of patients were female $(60,74.1 \%)$, Dominican (74, 96.1\%), unemployed $(64,78.8 \%)$, and did not complete secondary school (52, 67.5\%). Approximately equal proportions of patients were married $(28,35.4 \%)$ or single $(25,31.6 \%)$, with the remainder divorced, separated or widowed. The majority lived with family members (71, $89.9 \%$ ). Over $86 \%$ of patients stated pre-operatively that they believed their surgery had at least a $90 \%$ success rate.

\section{Internal Consistency of Outcome Measures}

The Cronbach's alpha coefficient for each of the WOMAC and SF-36 subscales measured at baseline and post-operatively was greater than 0.75 (Table 2), exceeding the generally acceptable threshold of internal consistency of 0.7 [35]. Of note, the internal consistency of each scale differed between patients who completed secondary school and those who did not, with the less educated group having Cronbach's alpha coefficients that were about 10$15 \%$ lower on each scale. For example the Cronbach alpha for the SF-36 physical function scale was 0.89 for those who completed secondary school and 0.77 for those who did not. These differences in internal consistency across educational strata were not noted at follow-up, although the sample size was considerably smaller.

\section{Pre-Operative Pain and Functional Status}

Pre-operatively, patients reported poor scores for physical function as measured by WOMAC (mean $=33.6$, sd $=22.0$ ) and SF-36 scales (mean $=16.5$, $\mathrm{sd}=16.1 ; 100$ is best possible score on these scales and 0 is worst). Patients also reported substantial pain $($ mean $=38.4$, sd $=22.9)$ and stiffness (mean $=34.3$, sd $=26.5$ ) as measured by the WOMAC indices. In contrast, patients scored high on the SF-36 mental health scale (mean $=76$, sd $=17.6$ ). Over half $(53.8 \%)$ of the patients rated their overall health as "good," "very good" or "excellent." The pre-operative clinical characteristics of the cohort are presented in Table 2

Table 3 shows the association between sex, age, number of joints replaced, and hip $v s$ knee patients and pre-operative clinical characteristics. Women reported significantly worse WOMAC scores for pain, stiffness and function than men. These differences were considerable: for example the WOMAC function score was 17.5 points higher (better) in men than in women. The SF-36 physical function score was also better in men, although this result was not statistically 
Table 1. Patient Characteristics

\begin{tabular}{|c|c|c|}
\hline Demographic Data & Mean (sd) & Range \\
\hline \multirow[t]{2}{*}{ Age } & $60.8(12.2)$ & $21-80$ \\
\hline & Number & Percent \\
\hline \multicolumn{3}{|l|}{ Gender } \\
\hline Female & 60 & 74.1 \\
\hline Male & 21 & 25.9 \\
\hline \multicolumn{3}{|l|}{ Country of origin } \\
\hline DR & 74 & 96.1 \\
\hline Other country & 3 & 3.9 \\
\hline \multicolumn{3}{|l|}{ Socioeconomic Characteristics } \\
\hline \multicolumn{3}{|l|}{ Marital status } \\
\hline Single & 25 & 31.6 \\
\hline Married & 28 & 35.4 \\
\hline Divorced or separated & 11 & 14.0 \\
\hline Widower & 15 & 19.0 \\
\hline \multicolumn{3}{|l|}{ Living situation } \\
\hline Alone & 5 & 6.3 \\
\hline with spouse and/or other family & 30 & 38.0 \\
\hline with friends & 2 & 2.5 \\
\hline with children (no spouse) & 41 & 51.9 \\
\hline \multicolumn{3}{|l|}{ Work status } \\
\hline Working & 17 & 21.3 \\
\hline Not working & 63 & 78.8 \\
\hline \multicolumn{3}{|l|}{ Education } \\
\hline Less than secondary school & 23 & 29.9 \\
\hline Secondary school, but did not graduate & 29 & 37.7 \\
\hline Graduated from secondary school & 13 & 16.9 \\
\hline Post secondary school + & 12 & 15.6 \\
\hline \multicolumn{3}{|l|}{ Joint Replaced } \\
\hline \multicolumn{3}{|l|}{ Knee } \\
\hline Unliteral & 34 & 42.0 \\
\hline Bilateral & 21 & 25.9 \\
\hline \multicolumn{3}{|l|}{ Hip } \\
\hline Unilateral & 20 & 24.7 \\
\hline Bilateral & 6 & 7.4 \\
\hline \multicolumn{3}{|l|}{ Perception of Total Joint Replacement } \\
\hline $\begin{array}{l}\text { Perception that surgery has a }>90 \% \\
\text { chance of relieving pain }\end{array}$ & 66 & 85.7 \\
\hline $\begin{array}{l}\text { Perception that the probability of } \\
\text { experiencing a major surgical } \\
\text { complication is }<1 \%\end{array}$ & 51 & 68.0 \\
\hline Pre-operative scores & Mean & Sd \\
\hline WOMAC* pain & 38.4 & 22.9 \\
\hline WOMAC* ${ }^{*}$ stiffness & 34.3 & 26.5 \\
\hline WOMAC* function & 33.6 & 22.0 \\
\hline SF-36* mental health & 76.0 & 17.6 \\
\hline \multirow[t]{2}{*}{ SF-36* physical function } & 16.5 & 16.1 \\
\hline & Number & Percent \\
\hline \multicolumn{3}{|l|}{ Self-rated health } \\
\hline Excellent & 12 & 15.4 \\
\hline Very Good & 14 & 17.9 \\
\hline Good & 16 & 20.5 \\
\hline Fair & 30 & 38.5 \\
\hline Poor & 6 & 7.7 \\
\hline
\end{tabular}

$*(0-100,100=$ best $)$ significant. In addition, compared to patients undergoing unilateral joint replacement, those receiving bilateral prostheses reported worse unadjusted scores in those same four measures. The differences were statistically significant for each measure except WOMAC stiffness. Age itself did not appear to affect scores no any of these measures. With respect to the SF-36 Mental Health Index and self-rated health, there were also no significant differences among any of the subgroups. Patients undergoing total hip replacement scored higher on all scales by approximately 5 points as compared to patients undergoing total knee replacement, although the differences were not statistically significant.

Table 2. Cronbach's Alpha Values of Health Status Measures

\begin{tabular}{|c|c|c|}
\hline \multirow{2}{*}{ Measures } & \multicolumn{2}{|c|}{ Cronbach's Alpha* } \\
\cline { 2 - 3 } & Pre-Operative & Follow-Up \\
\hline \hline WOMAC Pain & 0.79 & 0.83 \\
\hline WOMAC Stiffness & 0.76 & 0.83 \\
\hline WOMAC Function & 0.95 & 0.87 \\
\hline SF-36 Mental Health & 0.75 & 0.84 \\
\hline SF-36 Physical Function & 0.84 & 0.87 \\
\hline *The generally accepted threshold for acceptable internal consistency is a Cronbach's
\end{tabular}
alpha value of 0.7 .

\section{Post-Operative Clinical Outcomes and Improvement}

Table 4 shows the one year post-operative SF-36 and WOMAC scores and change in scores for the 28 patients who were surveyed both pre-operatively and postoperatively. The pre-operative scores for this group are also included in the table. Overall, patients showed significant improvement in all measures of pain and function. Patients undergoing hip vs knee replacement achieved similar gains in all scales resulting in comparable post-operative scores in pain and function. The average WOMAC pain score of the cohort improved by over 50 points for a mean post-operative score of $86.4(\mathrm{sd}=13.1) .92 .6 \%$ of patients reported experiencing significant or complete pain relief and 33.3\% of patients reported no pain, scoring perfectly (100 points) on the WOMAC pain assessment. Physical function as measured by the WOMAC and SF-36 scales improved by approximately 60 points each for mean final scores of 88.1 points $(\mathrm{sd}=11.4)$ and 74.7 points $(\mathrm{sd}=19.5)$ respectively. Fifty-seven percent of patients reported little or no difficulty in performing any of the activities assessed by the WOMAC function subscale. Ninety-three percent of patients rated their ability to perform daily activities as "much better." To provide a specific example of improvement in physical function, $50 \%$ of patients experienced extreme difficulty in climbing up stairs pre-operatively as opposed to none one year post-operatively. There was a modest improvement in SF-36 mental health score from a mean of 74.3 points $(\mathrm{sd}=$ 17.1) pre-operatively to 88.6 points $(\mathrm{sd}=14.6)$ one year following surgery. A comparison of pre- and post-op scores is shown in Fig. (1). 92.6\% of patients reported feeling very satisfied with the outcome of their surgery, $3.7 \%$ felt a little satisfied and $3.7 \%$ felt a little unsatisfied. 
Table 3. Mean Baseline Outcome Scores Stratified by Sex, Number of Joints Replaced, Age and Joint Replaced

\begin{tabular}{|c|c|c|c|c|c|c|c|c|c|c|c|c|}
\hline & \multicolumn{12}{|c|}{ Covariates } \\
\hline & \multicolumn{3}{|c|}{ Sex } & \multicolumn{3}{|c|}{ Number of Joints Replaced } & \multicolumn{3}{|c|}{ Age } & \multicolumn{3}{|c|}{ Joint Replaced } \\
\hline & Male & Female & p-Value & Unilateral & Bilateral & p-Value & $<60$ & $\geq 60$ & p-Value & Hip & Knee & p-Value \\
\hline WOMAC pain & 47.8 & 35.4 & 0.045 & 43.0 & 29.1 & 0.012 & 36.4 & 40.0 & 0.497 & 41.5 & 36.7 & 0.3879 \\
\hline WOMAC Stiffness & 46.7 & 30.1 & 0.010 & 37.0 & 29.6 & 0.173 & 34.9 & 33.8 & 0.755 & 37.5 & 32.8 & 0.3793 \\
\hline WOMAC Function & 46.5 & 29.0 & 0.001 & 38.6 & 23.6 & 0.006 & 31.6 & 35.1 & 0.583 & 36.6 & 32.1 & 0.4182 \\
\hline SF-36 Mental Health & 76.4 & 75.8 & 0.935 & 76.1 & 75.7 & 0.928 & 81.1 & 72.1 & 0.037 & 80.6 & 73.8 & 0.0919 \\
\hline SF-36 Physical Function & 23.5 & 14.0 & 0.248 & 19.0 & 11.7 & 0.048 & 19.7 & 13.9 & 0.255 & 18.4 & 15.5 & 0.7121 \\
\hline
\end{tabular}

\section{DISCUSSION}

To the best of our knowledge, this is the first study to critically assess the pre-operative health status and to evaluate the effects of TJR on self-reported health status for patients in a developing country receiving care from a medical relief service organization. Prior research has suggested that factors such as low pre-operative functional status and poorly controlled co-morbidities are associated with worse final results and thus may mitigate against good outcomes on such patients $[15,16,31]$. For example, a prospective cohort study of 175 patients with OA undergoing total hip or knee replacement found that patients with worse pre-operative health status did not achieve the same improvement in function and pain assessed by the SF-36 and WOMAC scales measured six months and two years postoperatively, as compared to patients starting with better preoperative health statuses $[15,31]$. Another study of 860 patients undergoing total knee arthroplasty found that low pre-operative scores and a higher number of co-morbidities were predictors of worse scores on pain and function assessed by the WOMAC and SF-36 scales one and two years post-operatively [16]. However, we document that the patients in our cohort achieved significant gains in physical function, experienced dramatic reductions in pain and reported high satisfaction with the overall results of the operation. Specifically, our patients' level of improvement of an average of 50 points on the WOMAC pain scale and 60 points on the WOMAC and SF-36 physical function scales is high in comparison to several other prospective cohort studies. For example, in the prospective cohort study of 860 patients described above [16], the average one year postoperative improvement in WOMAC pain and function scales was approximately 35 points and 30 points, respectively. Similarly, in the study of 175 patients undergoing total hip and knee replacement, patients improved in the SF-36 physical function scale by approximately 37 points and 28 points, respectively [15]. Thus the dramatic improvement in pain, function, and health status in our cohort suggests that poor pre-operative status and socioeconomic factors may not preclude good outcomes on patients participating in medical relief initiatives.

Our study builds upon prior research on the effect of TJR in developed countries, extending many of the findings documented in the United States, the United Kingdom and Australia to the Dominican Republic, to a small cohort of patients in the Dominican Republic.

Studies have consistently shown that women present for TJR at a later stage of functional decline and with greater pain than their male counterparts $[5,16-18,36]$ For example, in a study involving 323 patients undergoing total hip or knee replacement in the United States, women undergoing reported worse physical functional status, as measured by the Intermediate Activity of Daily Living (IADL) scale, than their male counterparts for both procedures. Specifically, women scored on average 9.1 points lower than males for knee surgery and 19.7 points lower for hip surgery on the 0 100 IADL scale (100 is best) [18]. Researchers have hypothesized that this discrepancy is due to gender differences in preference for or access to TJR $[17,18]$. That is, women may wait until they have suffered from greater functional deterioration due to arthritis before electing to undergo surgery and TJR may be offered less readily to women than to men. In our cohort of Dominican patients, we also found that women had worse pain and functional status

Table 4. Pre-Operative, Post-Operative and Change in Scores

\begin{tabular}{|c|c|c|c|c|c|c|c|c|c|}
\hline \multirow{3}{*}{ Measures } & \multicolumn{9}{|c|}{ Mean Scores (sd) } \\
\hline & \multicolumn{3}{|c|}{ Pre-Operative } & \multicolumn{3}{|c|}{ Post-Operative } & \multicolumn{3}{|c|}{ Change } \\
\hline & Overall & Hip & Knee & Overall & Hip & Knee & Overall & Hip & Knee \\
\hline WOMAC pain & $31.9(21.0)$ & $33.6(26.5)$ & $30.5(16.5)$ & $86.4(13.1)$ & $85.9(16.4)$ & $86.8(10.9)$ & $+53.1(26.9)$ & $52.3(34.5)$ & $53.8(19.7)$ \\
\hline WOMAC stiffness & $31.9(22.0)$ & $31.8(23.3)$ & $32.0(21.9)$ & $84.7(22.8)$ & $83.0(29.7)$ & $85.9(17.6)$ & $+52.4(33.2)$ & $51.1(38.5)$ & $53.3(30.1)$ \\
\hline WOMAC function & $28.4(20.3)$ & $29.1(26.1)$ & $28.0(16.3)$ & $88.1(11.4)$ & $88.5(12.8)$ & $88.0(10.9)$ & $+59.7(23.0)$ & $59.4(26.1)$ & $59.9(21.5)$ \\
\hline SF-36 mental health & $74.3(17.1)$ & $82.2(18.0)$ & $69.2(14.9)$ & $88.6(14.6)$ & $92.0(10.9)$ & $86.3(16.6)$ & $+14(16.7)$ & $9.8(11.2)$ & $16.9(19.5)$ \\
\hline SF-36 physical function & $14.3(17.9)$ & $15.7(23.9)$ & $13.4(13.1)$ & $74.7(19.5)$ & $76.7(22.5)$ & $73.4(17.9)$ & $+61.1(24.3)$ & $59.9(25.6)$ & $61.9(24.2)$ \\
\hline
\end{tabular}




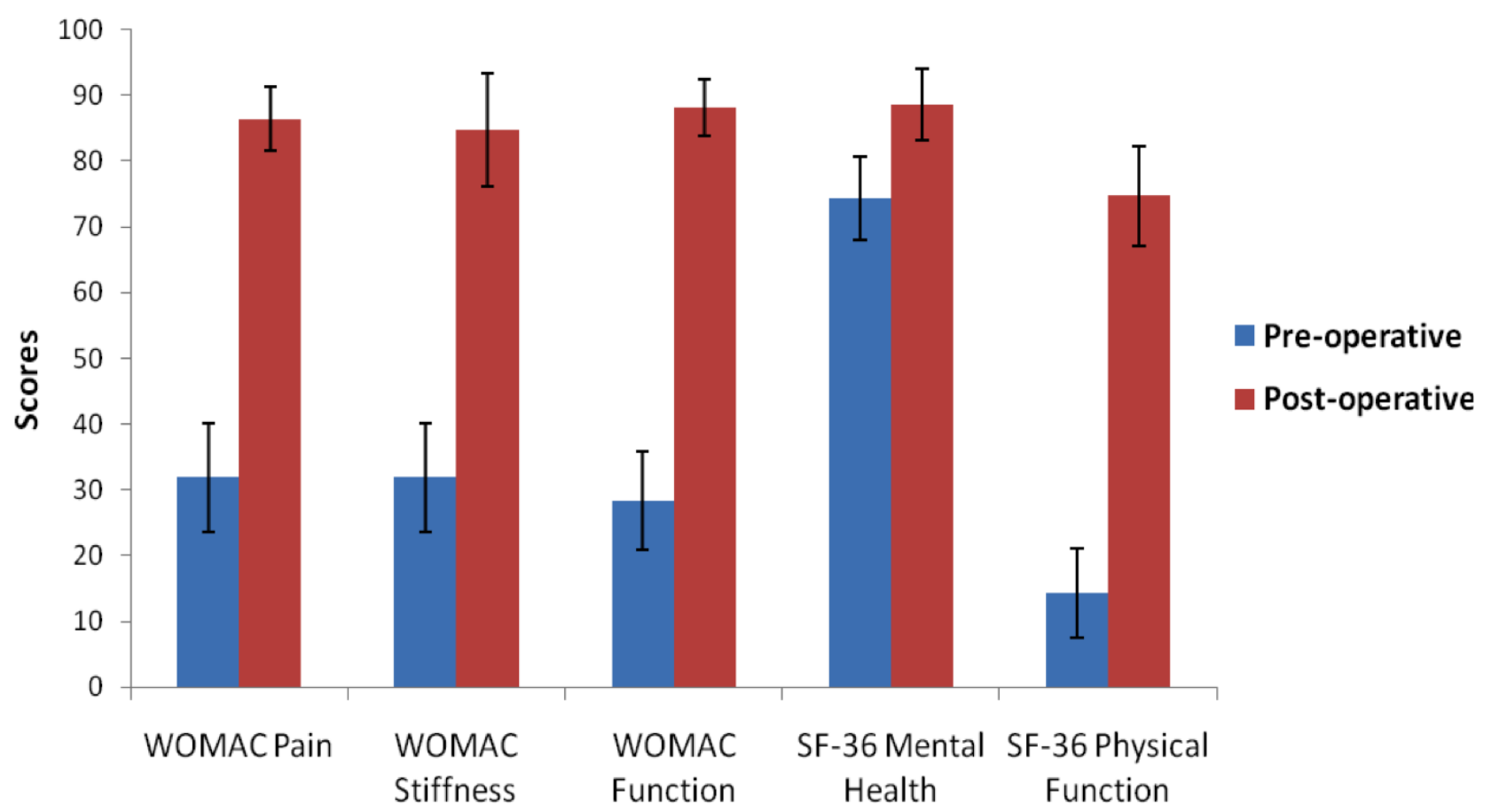

Fig. (1). Comparison of Pre-op and Post-op Measures. This figure shows pre- and post-operative mean scores for WOMAC pain, stiffness, function and SF-36 Mental Health and Physical Function for the 28 patients surveyed at both time intervals. Pre-operative scores are represented by blue bars and post-operative scores are represented by red bars. Error bars are shown to provide $95 \%$ confidence intervals for each of scores.

at the time of surgery. These differences were statistically significant and were greater than the established minimally clinical important differences (MCID) for each of the subscales (7.5 for WOMAC pain, 7.2 for WOMAC stiffness, 6.7 for WOMAC function, and 7.8 for SF-36 physical function) [37]. Explanations in addition to the ones proposed above in developed countries may help to explain this discrepancy. For example, Dominican women may have stronger social support networks that help them to compensate for their functional limitations. In addition, the tasks that they need to compensate for may be less physically demanding than those performed by men. Further research is needed to explore the cultural factors that mediate this discrepancy.

Our study also provides further support for the internal consistency of the WOMAC pain, function and stiffness scales and the SF-36 physical function and mental health subscales. Prior research using these measures in developed countries has demonstrated high internal consistency with Cronbach alpha values ranging from 0.95 to 0.97 for WOMAC scales [38] and values greater than 0.90 for the SF-36 subscales [39]. The somewhat lower Cronbach alpha values in our sample (Table 1) appear to be related in part to educational attainment. At baseline, the internal consistency for each of the scales was higher for those who achieved at least a secondary school education compared to those who did not. Still, Cronbach alpha values for all scales are above 0.7 suggesting that these measures are acceptable for reliable assessment of pain, function and mental health status in Dominican participants. Further research on cultural differences in how patients report health status and on the cultural-specific ways that arthritis affects patients' lives may help to tailor scales for patients in a developing country.
Our study was limited by the involvement of 81 patients including only 28 evaluated at both baseline and one year follow-up. In addition, patients were selected by the OpWalk team as those with the most advanced forms of arthritis and with substantial financial need. These patients may not be representative of the arthritic Dominican population. Both of these factors limit the generalizability of our results. However, since the patients in our cohort represent those with the most severe forms of arthritis, the outcomes reported in our study may be a conservative estimate of the gains that could be achieved following TJR if a greater proportion of patients with advanced arthritis in the Dominican Republic were able to participate in programs such as OpWalk.

\section{CONCLUSION}

Our study suggests that TJR performed by American surgeons participating in a medical relief organization is typically successful in relieving pain and restoring ability to perform functional activities for a small group of Dominican patients. These quantitative results provide a benchmark for evaluating outcomes achieved by such relief organizations. In addition, the significant gains in health-related quality of life documented in this pilot project justify larger studies of the outcome of TJR in developing world settings, with longer follow-up periods. Total joint replacement is currently largely unavailable to the majority of the population in developing countries such as the Dominican Republic. If the operation is shown to be successful as suggested by these data, efforts should be made to increase access to TJR. This would entail capacity building and design of care delivery systems that allow for host countries to perform these surgeries independently. In addition to the structural, 
operational and supply needs for successful delivery of this type of surgery, educating local care teams (surgeons, nurses, physical therapists and operating room personnel) is another important component of a sustainable solution to TJR in developing countries. Our work can serve as a standard to evaluate the performance of these programs each step of the way in the progression from medical relief program to autonomous TJR program staffed by the host facility. Lastly, arthritis is a paradigmatic chronic disease. As the global population ages and grows leading to an increased prevalence of chronic disease in developing nations, it will become ever more important to focus efforts on understanding and treating these conditions, including tailoring the efforts of medical relief organizations to best address the needs of these patients throughout the continuum of care.

\section{ACKNOWLEDGEMENTS}

Supported by Operation Walk Boston, Massachusetts Arthritis Foundation, Harvard Medical School, Department of Orthopedic Surgery, Brigham and Women's Hospital, NIH K24 AR 02123, NIH P60 AR 47782

\section{ABBREVIATIONS}

$\begin{array}{ll}\text { WOMAC }= & \text { Western Ontario and McMaster University } \\ & \text { Osteoarthritis } \\ \text { SF-36 } & \text { Short-Form } 36 \\ \text { OA } & =\text { Osteoarthritis } \\ \text { RA } & =\text { Rheumatoid Arthritis } \\ \text { TJR } & =\text { Total Joint Replacement } \\ \text { OpWalk }= & \text { Operation Walk } \\ \text { IADL } & =\text { Intermediate Activities of Daily Living } \\ \text { MCID } & =\text { Minimally Clinically Important Differences }\end{array}$

\section{REFERENCES}

[1] Woolf AD, Pfleger B. Burden of major musculoskeletal conditions. Bull World Health Organ 2003; 81(9): 646-56.

[2] Nugent R. Chronic diseases in developing countries: health and economic burdens. Ann N Y Acad Sci 2008; 1136: 70-9.

[3] Callahan CM, Drake BG, Heck DA, Dittus RS. Patient outcomes following tricompartmental total knee replacement: a metaanalysis. JAMA 1994; 271(17): 1349-57.

[4] Callahan CM, Drake BG, Heck DA, Dittus RS. Patient outcomes following unicompartmental or bicompartmental knee arthroplasty. a meta-analysis. J Arthroplasty 1995; 10(2): 141-50.

[5] Hawker G, Wright J, Coyte P, et al. Health-related quality of life after knee replacement. J Bone Joint Surg Am 1998; 80(2): 163-73.

[6] Heck DA, Robinson RL, Partridge CM, Lubitz RM, Freund DA. Patient outcomes after knee replacement. Clin Orthop Relat Res 1998; (356): 93-110.

[7] McGuigan FX, Hozack WJ, Moriarty L, Eng K, Rothman RH. Predicting quality-of-life outcomes following total joint arthroplasty. Limitations of the sf-36 health status questionnaire. J Arthroplasty $1995 ; 10(6): 742-7$.

[8] Ritter MA, Albohm MJ, Keating EM, Faris PM, Meding JB. Comparative outcomes of total joint arthroplasty. J Arthroplasty 1995; 10(6): 737-41.

[9] Chang RW, Pellisier JM, Hazen GB. A cost-effectiveness analysis of total hip arthroplasty for osteoarthritis of the hip. JAMA 1996; 275(11): 858-65.

[10] Harris WH, Sledge CB. Total hip and total knee replacement (1). N Engl J Med 1990; 323(11): 725-31.

[11] Insall JN, Binazzi R, Soudry M, Mestriner LA. Total knee arthroplasty. Clin Orthop Relat Res 1985; (192): 13-22.
[12] Townley CO. Total knee arthroplasty: a personal retrospective and prospective review. Clin Orthop Relat Res 1988; (236): 8-22.

[13] Losina E, Walensky RP, Kessler CL, et al. Cost-effectiveness of total knee arthroplasty in the united states: Patient risk and hospital volume. Arch Intern Med 2009; 169(12): 1113-21; discussion 21-2.

[14] Agency for Healthcare Research and Quality. Rockville, MD; [cited March 9, 2011]; Available from: http: //hcupnet.ahrq.gov/

[15] Fortin PR, Penrod JR, Clarke AE, et al. Timing of total joint replacement affects clinical outcomes among patients with osteoarthritis of the hip or knee. Arthritis Rheum 2002; 46(12): 3327-30.

[16] Lingard EA, Sledge CB, Learmonth ID. Patient expectations regarding total knee arthroplasty: Differences among the united states, united kingdom, and australia. J Bone Joint Surg Am 2006; 88(6): 1201-7.

[17] Karlson EW, Daltroy LH, Liang MH, Eaton HE, Katz JN. Gender differences in patient preferences may underlie differential utilization of elective surgery. Am J Med 1997; 102(6): 524-30.

[18] Katz JN, Wright EA, Guadagnoli E, Liang MH, Karlson EW, Cleary PD. Differences between men and women undergoing major orthopedic surgery for degenerative arthritis. Arthritis Rheum 1994; 37(5): 687-94.

[19] Ibrahim SA, Siminoff LA, Burant CJ, Kwoh CK. Variation in perceptions of treatment and self-care practices in elderly with osteoarthritis: a comparison between african american and white patients. Arthritis Rheum 2001; 45(4): 340-5.

[20] Operation smile. [cited March 9, 2011]; Available from: http: //www.operationsmile.org/

[21] Dominican republic. Pan American Health Organization, World Health Organization; [cited]; Available from: http://www.paho. org/English/DD/AIS/cp_214.htm

[22] McHorney CA, Ware JE Jr, Lu JF, Sherbourne CD. The mos 36item short-form health survey (sf-36): Iii. Tests of data quality, scaling assumptions, and reliability across diverse patient groups. Med Care 1994; 32(1): 40-66.

[23] McHorney CA, Ware JE Jr, Raczek AE. The mos 36-item shortform health survey (sf-36): Ii. Psychometric and clinical tests of validity in measuring physical and mental health constructs. Med Care 1993; 31(3): 247-63.

[24] Ware JE Jr, Sherbourne CD. The mos 36-item short-form health survey (sf-36). I. Conceptual framework and item selection. Med Care 1992; 30(6): 473-83.

[25] Bellamy N, Buchanan WW, Goldsmith CH, Campbell J, Stitt LW. Validation study of womac: a health status instrument for measuring clinically important patient relevant outcomes to antirheumatic drug therapy in patients with osteoarthritis of the hip or knee. J Rheumatol 1988; 15(12): 1833-40.

[26] Bellamy N. Womac osteoarthritis index: a user's guide. London: ON 1995.

[27] Katz JN, Barrett J, Mahomed NN, Baron JA, Wright RJ, Losina E. Association between hospital and surgeon procedure volume and the outcomes of total knee replacement. J Bone Joint Surg Am 2004; 86-A(9): 1909-16.

[28] Katz JN, Losina E, Barrett J, et al. Association between hospital and surgeon procedure volume and outcomes of total hip replacement in the united states medicare population. J Bone Joint Surg Am 2001; 83-A(11): 1622-9.

[29] Katz JN, Mahomed NN, Baron JA, et al. Association of hospital and surgeon procedure volume with patient-centered outcomes of total knee replacement in a population-based cohort of patients age 65 years and older. Arthritis Rheum 2007; 56(2): 568-74.

[30] Katz JN, Phillips CB, Baron JA, et al. Association of hospital and surgeon volume of total hip replacement with functional status and satisfaction three years following surgery. Arthritis Rheum 2003; 48(2): 560-8.

[31] Fortin PR, Clarke AE, Joseph L, et al. Outcomes of total hip and knee replacement: preoperative functional status predicts outcomes at six months after surgery. Arthritis Rheum 1999; 42(8): 1722-8.

[32] Laupacis A, Bourne R, Rorabeck C, et al. The effect of elective total hip replacement on health-related quality of life. J Bone Joint Surg Am 1993; 75(11): 1619-26.

[33] Batlle-Gualda E, Esteve-Vives J, Piera MC, Hargreaves R, Cutts J. Adaptación transcultural del cuestionario womac específico para artrosis de rodilla y cadera. Rev Esp Reumatol 1999; 26: 38-45. 
[34] Alonso J. Cuestionario de salud sf-36. Barcelona, Spain; 1999 [updated 1999; cited 11/1/2009]; Available from: http://www.chim e.ucla.edu/measurement/SF-36\%20Spain.pdf

[35] Nunnally JC. Psychometric theory 2ed. New York: McGraw Hill 1978.

[36] Katz BP, Freund DA, Heck DA, et al. Demographic variation in the rate of knee replacement: a multi-year analysis. Health Serv Res 1996; 31(2): 125-40.

[37] Angst F, Aeschlimann A, Stucki G. Smallest detectable and minimal clinically important differences of rehabilitation intervention with their implications for required sample sizes using womac and sf-36 quality of life measurement instruments in patients with osteoarthritis of the lower extremities. Arthritis Rheum 2001; 45(4): 384-91.

[38] Whitehouse SL, Lingard EA, Katz JN, Learmonth ID Development and testing of a reduced womac function scale. J Bone Joint Surg Br 2003; 85(5): 706-11.

[39] Ware JE Jr, Snow KK, Kosinski M, Gandek B. Sf-36 health survey: Manual and interpretation guide. Boston, MA: Health Institute, New England Medical Center 1993.

This is an open access article licensed under the terms of the Creative Commons Attribution Non-Commercial License (http://creativecommons.org/licenses/by-nc/3.0/) which permits unrestricted, non-commercial use, distribution and reproduction in any medium, provided the work is properly cited. 